\title{
Analisis Kesesuaian Potensi Pengembangan Kawasan Minapolitan Berbasis Perikanan Budidaya di Kecamatan Purwanegara Kabupaten Banjarnegara
}

\author{
Analysis of the Potential for the Development of Minapolitan Area Based \\ on Cultivation Fisheries in Purwanegara, Banjarnegara Regency
}

\author{
Suwarsito ${ }^{1}$, Diana Indra Dewi ${ }^{2}$, Sutomo ${ }^{2}$ \\ ${ }^{1,2}$ Program Studi Pendidikan Geografi, FKIP, Universitas Muhammadiyah Purwokerto \\ 1'suwarsito@ump.ac.id
}

\begin{abstract}
ABSTRAK
Penelitian ini bertujuan untuk menganalisis kesesuaian potensi pengembangan kawasan minapolitan berbasis perikanan budidaya di Kecamatan Purwanegara Kabupaten Banjarnegara. Penelitian ini menggunakan metode survei. Populasi penelitian adalah kawasan minapolitan Kecamatan Purwanegara yang berjumlah 13 desa. Teknik pengambilan sampel menggunakan total sampling. Jenis data terdiri dari data primer dan data sekunder. Data primer berupa data potensi kawasan minapolitan di Kecamatan Purwanegara meliputi kondisi SDA, jenis budidaya, dan kondisi sarana prasarana. Data sekunder berupa data masterplan minapolitan Kabupaten Banjarnegara. Teknik pengumpulan data menggunakan metode observasi, wawancara, dan dokumentasi. Pengolahan data menggunakan tabulasi. Analisis data dilakukan secara deskriptif kualitatif dan matching data. Deskripsi kualitatif dilakukan untuk menjelaskan potensi perikanan budidaya di Kecamatan Purwanegara. Matching data dilakukan untuk mengetahui kesesuaian potensi pengembangan kawasan minapolitan berbasis perikanan budidaya di Kecamatan Purwanegara dengan Peraturan Menteri Kelautan dan Perikanan Republik Indonesia Nomor: Per.18/Men/2012 tentang Pedoman Penyusunan Rencana Induk Pengembangan Kawasan Minapolitan. Hasil penelitian menunjukkan bahwa potensi pengembangan kawasan minapolitan berbasis perikanan budidaya di Kecamatan Purwanegara terdapat 8 aspek yang memiliki kesesuaian dengan persyaratan pengembangan kawasan minapolitan yang tertuang dalam Peraturan Menteri Kelautan dan Perikanan Republik Indonesia Nomor: Per.18/Men/2012 dengan presentase kesesuaian $88,88 \%$.
\end{abstract}

Kata-kata kunci: minapolitan, pengembangan kawasan, perikanan budidaya

\begin{abstract}
This study aims to analyze the suitability of the potential development of aquaculturebased minapolitan areas in Purwanegara District, Banjarnegara Regency. This research uses survey method. The study population is the Minapolitan area Purwanegara District, which amounted to 13 villages. The sampling technique uses total sampling. The type of data consists of primary data and secondary data. Primary data in the form of data on the potential of the minapolitan area in Purwanegara District include the condition of natural resources, the type of cultivation, and the condition of infrastructure. Secondary data in the form of minapolitan masterplan Banjarnegara Regency. Data collection techniques using the method of observation, interviews, and documentation. Data
\end{abstract}


processing using tabulation. Data analysis was performed by descriptive qualitative and matching data. Qualitative description is carried out to explain the potential of aquaculture in Purwanegara District. Data matching was conducted to determine the suitability of the potential development of aquapulture-based minapolitan areas in Purwanegara District with the Regulation of the Minister of Maritime Affairs and Fisheries of the Republic of Indonesia Number: Per.18 / Men / 2012 concerning Guidelines for the Preparation of a Minapolitan Area Development Master Plan. The results showed that the potential for the development of aquaculture-based minapolitan areas in Purwanegara District, there are 8 aspects that are in conformity with the requirements for developing minapolitan areas as stipulated in the Regulation of the Minister of Maritime Affairs and Fisheries of the Republic of Indonesia Number: Per.18 / Men / 2012 with conformity percentage of $88.88 \%$.

Keywords: minapolitan, area development, aquaculture

\section{PENDAHULUAN}

Pengembangan kawasan adalah usaha untuk membangun dan meningkatkan saling ketergantungan dan interaksi antara sistem ekonomi, manusia atau masyarakat, dan lingkungan hidup beserta sumber daya alam yang ada di dalamnya dalam satu ekosistem. Salah satu wujud pengelolaan dan pengembangan sumberdaya alam yang berupa potensi perikanan yaitu konsep minapolitan, Indonesia menerapkan konsep minapolitan, dimana titik fokus perkembangan wilayah berkaitan dengan potensi laut atau perikanan suatu wilayah. Perencanaan pengembangan kawasan perikanan budidaya (minapolitan) merupakan salah satu upaya untuk memanfaatkan lahan/wilayah yang ada yang memiliki potensi yang relatif menjanjikan kesejahteraan masyarakat tertentu.

Konsep minapolitan adalah pengembangan basis kelautan dan perikanan yang bertujuan untuk meningkatkan kesejahteraan masyarakat perikanan dengan mengurangi kesenjangan yang terjadi di dalamnya (Nurmarini, 2018). Minapolitan merupakan konsep manajemen ekonomi kawasan berbasis kelautan dan perikanan. Program ini merupakan upaya untuk merevitalisasi sentra produksi perikanan dan kelautan dengan fokus pada peningkatan produksi dan pendapatan rakyat setempat di daerah tersebut. Program pengembangan kawasan sentra perikanan adalah pembangunan ekonomi berbasis perikanan yang dilaksanakan dengan jalan mensinergikan berbagai potensi yang ada, utuh dan menyeluruh, berdaya saing relatif tinggi, berbasis kerakyatan, berkelanjutan atau bersifat dinamis dan terdesentralisasi yang digerakkan oleh masyarakat dan difasilitasi oleh pemerintah.

Kecamatan Purwanegara merupakan salah satu Kecamatan di Kabupaten Banjarnegara yang kaya akan sumberdaya alam, terutama hasil pertanian dan perikanan. Selain di kenal sebagai daerah pertanian, Kecamatan Purwanegara merupakan salah satu daerah penghasil produksi perikanan budidaya air tawar yang besar dan merupakan salah satu kawasan minapolitan di Kabupaten Banjarnegara yang memiliki nilai pasar ekspor ke daerah hingga ke luar daerah. Penetapan Kecamatan Purwanegara sebagai kawasan minapolitan yaitu berdasarkan Keputusan Menteri Kelautan dan Perikanan Republik Indonesia Nomor 35/KEPMEN KP/2013.

Wilayah perencanaan dalam penelitian ini meliputi 13 Desa yang terdapat di Kecamatan Purwanegara. Pemilihan lokasi studi ini berdasarkan jumlah produksi perikanan paling banyak di kecamatan ini. Selain itu, Kecamatan Purwanegara memiliki Pasar Ikan terbesar di Jawa Tengah yang mendukung pengembangan kawasan Minapolitan karena potensi perikanan yang dimiliki. 
Selama ini beberapa penelitian telah dilakukan untuk mengkaji pengembangan minapolitan di Indonesia. Muchlisin et al., (2012) telah melakukan pemetaan potensi daerah untuk pengembangan kawasan minapolitan di beberapa lokasi Provinsi Aceh. Rudiono et al., (2013) telah melakukan evaluasi pelaksanaan program minapolitan tahun 2009-2011 di Kabupaten Banyumas. Ambasari et al. (2013) mengkaji strategi pengembangan kawasan perikanan budidaya di kabupaten lampung timur. Sedangkan Arifin et al., 2013 telah melakukan analisis tipologi wilayah dalam mendukung pengembangan minapolitan di Provinsi Gorontalo. Penelitian Adhihapsari et al. (2014) telah mengkaji perencanaan pengembangan wilayah Kawasan Minapolitan Budidaya di Gandusari Kabupaten Blitar. Hasil penelitian Arnawa et al. (2017) telah berhasil melakukan pemetaan pada sentra produksi, pengolahan, pemasaran, dan pusat pelayanan minapolitan di Kabupaten Gianyar. Fatmawaty et al., (2018) telah melakukan penelitian mengenai strategi pengembangan kawasan minapolitan di Kecamatan Pamboang Kabupaten Majene Nurmarini (2018) mengkaji pengembangan area minapolitan berbasis perencanaan partisipasi masyarakat di Desa Sei Ijum Raya, Kabupaten Kotawaringin Timur.

Pengembangan minapolitan Kecamatan Purwanegara belum banyak dilakukan pengkajian di wilayah tersebut. Oleh karena itu, dilakukan penelitian dengan tujuan untuk mengkaji potensi pengembagan kawasan minapolitan berbasis perikanan budidaya di Kecamatan Purwanegara, Kabupaten Banjarnegara dengan menggunakan Sistem Informasi Geografi (SIG).

\section{METODE}

Penelitian ini menggunakan metode survei. Populasi penelitian adalah kawasan minapolitan Kecamatan Purwanegara yang berjumlah 13 desa. Teknik pengambilan sampel menggunakan total sampling. Jenis data terdiri dari data primer dan data sekunder. Data primer berupa data potensi kawasan minapolitan di Kecamatan Purwanegara meliputi kondisi SDA, jenis budidaya, dan kondisi sarana prasarana. Data sekunder berupa data masterplan minapolitan Kabupaten Banjarnegara. Teknik pengumpulan data menggunakan metode observasi, wawancara, dan dokumentasi. Pengolahan data menggunakan tabulasi. Analisis data dilakukan secara deskriptif kualitatif dan matching data. Deskripsi kualitatif dilakukan untuk menjelaskan potensi perikanan budidaya di Kecamatan Purwanegara. Matching data dilakukan untuk megetahui kesesuaian potensi pengembangan kawasan minapolitan berabasis perikanan budidaya di Kecamatan Purwanegara dengan Peraturan Menteri Kelautan dan Perikanan Republik Indonesia Nomor Per.18/Men/2012 Tentang Pedoman Penyusunan Rencana Induk Pengembangan Kawasan Minapolitan.

\section{HASIL DAN PEMBAHASAN}

Kecamatan Purwanegara merupakan salah satu Kecamatan di Kabupaten Banjarnegara yang terletak $\pm 15 \mathrm{~km}$ di bagian barat dari Ibu Kota Kabupaten Banjarnegara dan $\pm 166 \mathrm{~km}$ di bagian barat dari Ibu kota Provinsi Jawa Tengah. Kecamatan Purwanegara terdiri dari 13 Desa dan memiliki luas wilayah 73,87 km².

Bila ditinjau dari bentuk tata alam dan penyebaran geografis, Kecamatan Purwanegara dibagi menjadi dua wilayah yaitu wilayah tengah dan selatan. Wilayah tengah terdiri dari wilayah dengan relief yang datar berupa lembah Sungai Serayu yang subur. Wilayah selatan, terdiri dari wilayah dengan relief yang curam yang merupakan bagian dari pegunungan Serayu. 
Kecamatan Purwanegara juga mempunyai ketinggian yang bervariasi karena letaknya yang berada pada jalur pegunungan. Kondisi wilayahnya terdiri atas dataran tinggi yang meliputi 4 desa yaitu Desa Kalitengah, Desa Petir, Desa Kaliajir dan Desa Karanganyar. Sedangkan sembilan desa lainnya merupakan daerah aliran sungai sampai dataran yaitu Desa Merden, Desa Mertasari, Desa Pucungbedug, Desa Parakan, Desa Kutawuluh, Desa Gumiwang, Desa Kalipelus, Desa Purwanegara, dan Desa Danaraja.

Kecamatan Purwanegara memperoleh pasokan air dari Sungai Serayu dan anakanak sungainya melalui saluran irigasi. Kecamatan Purwanegara dialiri oleh sungai yaitu Sungai Serayu, Sungai Uwat, Sungai Pucung, Sungai Batur, Sungai Lebak Menak, Sungai Pakuran, Sungai Sapi, Sungai Parakan, Sungai Blimbing, dan Sungai Tusan.

Sumber pengairan yang dimanfaatkan masyarakat perikanan di kawasan minapolitan Kecamatan Purwanegara ini adalah Daerah Irigasi Blimbing. Daerah irigasi tersebut merupakan sumber utama perairan bagi kelangsungan pertanian dan perikanan di kawasan minapolitan Kecamatan Purwanegara. Di samping dari irigasi, terdapat pula pembudidayaan ikan dengan memanfaatkan sumber air dari mata air, terutama untuk kegiatan pembenihan. Sedangkan untuk bak-bak permanen yang ukurannya relatif sempit banyak memanfaatkan air sumur.

Pengembangan wilayah pada hakikatnya ditujukan untuk menciptakan kesejahteraan masyarakat, peningkatan kualitas, peningkatan kemajuan wilayah serta mengurangi kesenjangan antar wilayah (Nurmarini, 2018). Minapolitan dilaksanakan melalui pengembangan kawasan di daerah-daerah potensial unggulan. Kawasan minapolitan dikembangkan melalui pembinaan sentra produksi yang berbasis pada sumber daya perikanan yang didukung oleh kerjasama antar elemen masyarakat dan instansi terkait, serta kelengkapan sarana dan prasarana guna menunjang pengembangan kawasan minapolitan.

Hasil analisis pengembangan kawasan minapolitan di Kecamatan Purwanegara, menunjukkan bahwa 8 aspek diantaranya sesuai dengan persyaratan pengembangan kawasan minapolitan menurut Peraturan Menteri Kelautan dan Perikanan Republik Indonesia Nomor Per.18/Men/2012 dengan presentase kesesuian sebesar 88,88 \%. Kedelapan aspek tersebut yaitu:

1. Kesesuaian dengan Rencana Strategis, Rencana Tata Ruang Wilayah (RTRW) dan/atau Rencana Zonasi Pengelolaan Wilayah Pesisir dan Pulau-Pulau Kecil (RZWP3-K) kabupaten/kota, serta Rencana Pengembangan Jangka Menengah Daerah (RPJMD) yang telah ditetapkan,

2. Memiliki komoditas unggulan di bidang kelautan dan perikanan dengan nilai ekonomi tinggi,

3. Letak geografis kawasan yang strategis dan secara alami memenuhi persyaratan untuk pengembangan produk unggulan kelautan dan perikanan,

4. Terdapat unit produksi, pengolahan, dan/atau pemasaran dan jaringan usaha yang aktif berproduksi, mengolah dan/atau memasarkan yang terkonsentrasi di suatu lokasi dan mempunyai mata rantai produksi pengolahan, dan/atau pemasaran yang saling terkait,

5. Tersedianya fasilitas pendukung berupa aksesibilitas terhadap pasar, permodalan, sarana dan prasarana produksi, pengolahan, dan/atau pemasaran, keberadaan lembagalembaga usaha, dan fasilitas penyuluhan dan pelatihan,

6. Kelayakan lingkungan diukur berdasarkan daya dukung dan daya tampung lingkungan, potensi dampak negatif, dan potensi terjadinya kerusakan di lokasi di masa depan,

7. Komitmen daerah, berupa kontribusi pembiayaan, personil, dan fasilitas pengelolaan dan pengembangan minapolitan,

8. Keberadaan kelembagaan pemerintah daerah yang bertanggung jawab di bidangnya 
Delapan aspek tersebut sudah terlaksana dalam pengembangan Kawasan Minapolitan di Kecamatan Purwanegara. Pengembangan kawasan Minapolitan Kecamatan Purwanegara terdapat dalam RTRW Kabupaten Banjarnegara 2011-2031 Pasal 54 huruf d, bahwa strategi untuk melaksanakan kebijakan peengembangan kawasan strategis daerah diantaranya adalah mengembangkan kawasan minapolitan yang terdiri dari 5 kecamatan yaitu Kecamatan Rakit, Mandiraja, Purwanegara, Bawang, dan Wanadadi (RAJAPURBAWA).

Aspek yang belum sesuai dengan persayaratan pengembangan kawasan minapolitan yaitu ketersediaan data dan informasi tentang kondisi dan potensi kawasan persyaratan pengembangan kawasan minapolitan. Dalam pengembangan kawasan minapolitan di Kecamatan Purwanegara, ketersediaan data dan informasi sudah tersedia namun informasi dan data yang tersedia sangat terbatas dan tidak uptodate (Gambar 1).

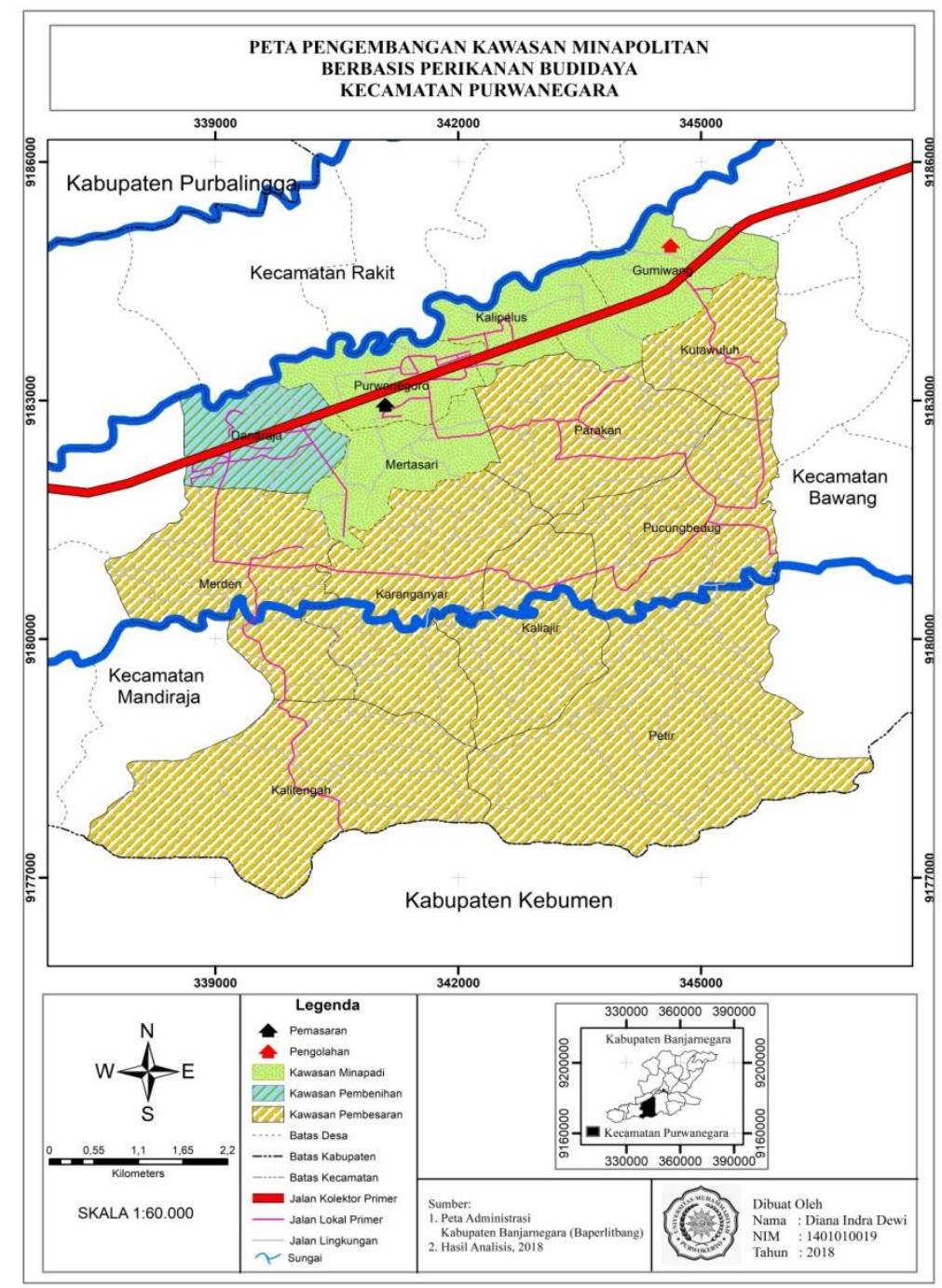

Gambar 1. Peta Pengembangan Kawasan Minapolitan Berbasis Perikanan Budidaya di Kecamatan Purwanegara, 2018 
Kecamatan Purwanegara memiliki potensi budidaya perikanan yang dikelola dan dikembangkan dengan baik. Penggarapan perikanan budidaya di Kecamatan Purwanegara difokuskan pada 4 jenis budidaya yaitu pembenihan, pembesaran, minapadi, serta pengolahan dan pemasaran. Adapun kondisi jenis budidaya perikanan pada setiap desa yaitu (Tabel 1).

Dalam pengembangannya, Kawasan Minapolitan Kecamatan Purwanegara memiliki komoditas unggulan yaitu ikan nila di Desa Gumiwang yang merupakan Kampung Nila. Namun untuk basis perikanan di Kecamatan Purwanegara terdiri dari jenis ikan mas, lele, tambakan, dan bawal (Tabel 2).

Berdasarkan hasil analisis LQ, komoditas basis yang ditunjukkan dengan nilai LQ tertinggi (LQ >1) adalah jenis ikan bawal yaitu sebesar 1,54 dengan jumlah produksi sebesar 2.956.000 ekor. Sedangkan jenis ikan lain berdasarkan hasil analisis LQ termasuk kedalam komoditas non basis terkecil karena memliki nilai LQ $<1$, diantaranya adalah ikan Mujair dengan nilai LQ sebesar 0,53.

Tabel 1. Kondisi jenis budidaya perikanan di Kecamatan Purwanegara

\begin{tabular}{clc}
\hline No & \multicolumn{1}{c}{ Desa } & Jenis Budidaya \\
\hline 1 & Kalitengah & Pembesaran \\
2 & Petir & Pembesaran \\
3 & Kaliajir & Pembesaran \\
4 & Karanganyar & Pembesaran \\
5 & Merden & Pembesaran \\
6 & Mertasari & Minapadi \\
7 & Parakan & Pembesaran \\
8 & Pucungbedug & Pembesaran \\
9 & Kutawuluh & Pembesaran \\
10 & Gumiwang & Minapadi \\
11 & Kalipelus & Minapadi \\
12 & Purwonegoro & Minapadi \\
13 & Danaraja & Pembenihan \\
\hline
\end{tabular}

Tabel 2. Hasil Analisis LQ di Kecamatan Purwanegara

\begin{tabular}{|c|c|c|c|c|c|c|c|}
\hline No & $\begin{array}{c}\text { Komoditi } \\
\text { Kecamatan }\end{array}$ & $\begin{array}{c}\text { Produksi } \\
\text { Komoditi } \\
\text { Kecamatan } \\
\quad(k g)\end{array}$ & $\begin{array}{c}\text { Total } \\
\text { Produksi } \\
\text { Komoditi } \\
\text { Kecamatan } \\
\text { (kg) }\end{array}$ & $\begin{array}{c}\text { Total } \\
\text { Produksi } \\
\text { Komoditi } \\
\text { Kecamatan } \\
\text { (kg) }\end{array}$ & $\begin{array}{c}\text { Total } \\
\text { Produksi } \\
\text { Kabupaten } \\
\text { (kg) }\end{array}$ & LQ & Basis \\
\hline 1 & Gurame & 8.900 .000 & & 47.800 .000 & & 0,76 & - \\
\hline 2 & Mas & 8.696 .000 & & 29.300 .000 & & 1,21 & $*$ \\
\hline 3 & Nila & 8.256 .000 & & 36.900 .000 & & 0,91 & - \\
\hline 4 & Lele & 23.534 .000 & & 82.000 .000 & & 1,17 & $*$ \\
\hline 5 & Tawes & 16.460 .000 & & 68.350 .000 & & 0,98 & - \\
\hline 6 & Tambakan & 2.726 .000 & 80.100 .000 & 10.160 .000 & 26.470 .000 & 1,09 & $*$ \\
\hline 7 & Mujair & 2.080 .000 & & 16.060 .000 & & 0,53 & - \\
\hline 8 & Nilem & 4.790 .000 & & 16.913 .000 & & 1,15 & $*$ \\
\hline 9 & Patin & 1.702 .000 & & 11.157 .000 & & 0,62 & - \\
\hline 10 & Bawal & 2.956 .000 & & 7.830 .000 & & 1,56 & $*$ \\
\hline
\end{tabular}

Sumber : Dinas Pertanian,Peternakan dan Perikanan Kab.Banjarnegara, 2012

Keterangan: $*=$ Komoditas basis , nilai LQ> $1 ;-=$ Komoditas non basis, nilai LQ 
Pada komoditas yang memiliki nilai LQ $>1$, artinya komoditas ikan tersebut dapat memenuhi konsumsi di daerah Kecamatan Purwanegara dan juga konsumsi daerah lain (potensi ekspor). Sedangkan untuk komoditas lainnya yang memiliki nilai LQ $<1$, berarti komoditas ikan tersebut tidak mencukupi untkuk konsumsi di Kecamatan Purwanegara dan memasok ke daerah lainnya.

Kecamatan Purwanegara memiliki letak geografis yang strategis karena dilalui jalur tengah trans Jawa dengan jaringan jalan kelas nasional yang menghubungkan beberapa kota besar di Pulau Jawa seperti Jakarta-Yogyakarta dan Semarang. Selain itu, Kecamatan Purwanegara dilalui jaringan jalan yang menghubungkan jalur utama dengan beberapa kabupaten di sekitar Kabupaten Banjarnegara yaitu Kabupaten Banyumas, Kabupaten Purbalingga, Kabupaten Wonosobo, dan Kabupaten Kebumen. Oleh karena letaknya yang strategis, kawasan minapolitan di Kecamatan Purwanegara memiliki unit pemasaran yang luas yang dikelola oleh kelompok pembudidaya perikanan untuk dipasarkan ke daerah sekitarnya ataupun ke luar daerah Kecamatan Purwanegara, baik pasar lokal maupun regional seperti Jawa Tengah, Jawa Barat, Yogyakarta, Jakarta, dan luar Pulau Jawa.

Selain unit produksi dan pemasaran juga terdapat unit pengolahan hasil perikanan budidaya di Kecamatan Purwanegara. Unit produksi mencakup unit produksi yang dikelola oleh pemerintah maupun unit produksi yang dioperasikan secara lembaga oleh masayarakat setempat seperti Pokdakan (Kelompok Pembudidaya Perikanan) yaitu Kelompok Mina lestari Kalipelus, Kelompok Minagati Kalipelus, dan UPR Minadadi Rejeki Gumiwang yang terkonsentrasi pada produksi kampung nila.

Pengembangan kawasan minapolitan di Kecamatan Purwanegara membutuhkan lembaga pendukung maupun lembaga yang akan mengelola minapolitan, baik swasta maupun pemerintah. Pengelolaan tersebut melibatkan beberapa sektor yaitu keuangan, pemerintahan, lingkungan, pendidikan, kesehatan, keamanan dan petanian.

\section{KESIMPULAN}

Berdasarkan hasil penelitian menunjukan bahwa potensi pengembangan kawasan minapolitan berbasis perikanan budidaya di Kecamatan Purwanegara sesuai dengan Peraturan Menteri Kelautan dan Perikanan Republik Indonesia Nomor PER.18/MEN/2012 Tentang Pedoman Penyusunan Rencana Induk Pengembangan Kawasan Minapolitan dengan presentase kesesuaian sebesar 88,88\%. Hal ini ditunjukkan dengan adanya 8 aspek dari 9 aspek yang diteliti sesuai untuk pengembangan kawasan minapolitan di Kecamatan Purwanegara. Namun terdapat satu aspek yang belum sesuai dengan persyaratan pengembangan kawasan minapolitan yaitu kurangnya ketersediaan data dan informasi tentang kondisi dan potensi kawasan pengembangan kawasan minapolitan.

Berdasarkan hasil penelitian yang telah dilakukan, saran bagi pemerintah yaitu lebih fokus dalam mengembangkan minapolitan di Kecamatan Purwanegara, dengan melakukan perbaikan dan kelengkapan dalam ketersedian data dan informasi mengenai potensi pengembangan kawasan minapolitan di Kecamatan Purwanegara serta melakukan pendataan secara detail tentang informasi mengenai status budidaya perikanan di Kecamatan Purwanegara.

\section{DAFTAR PUSTAKA}

Adhihapsari, W.,B. Semedi, M. Mahmudi. 2014. Perencanaan Pengembangan Wilayah Kawasan Minapolitan Budidaya di Gandusari Kabupaten Blitar. J-PAL, Vol. 5 (2): $7-14$. 
Ambasari, L., K. Gandasasmita, U. Sudadi. 2013. Strategi Pengembangan Kawasan Perikanan Budidaya di Kabupaten Lampung Timur. Globe. Vol. (15) 2 : 137 -145

Arifin, T., T.L. Kepel, S.N. Amri. 2013. Analisis Tipologi Wilayah dalam Mendukung Pengembangan Minapolitan di Provinsi Gorontalo. TATA LOKA, Vol. 5 (2): 129 139.

Arnawa, I.K., I.G.B. Udayana, G.A.G.E. Martini ngsih, I.M. Sukerta. 2017. Development Concept Plan of Minapolitan Regions in Gianyar Bali Indonesia. International Research Journal of Engineering, IT \& Scientific Research, Vol. 3 (6): 11-20.

Fatmawaty, D, Ikawati, dan E. Amri. 2018. Strategi Pengembangan Kawasan Minapolitan Di Kecamatan Pamboang Kabupaten Majene Dalam Konsep Pengembangan Wilayah. PLANO MADANI, Vol. 7 (1): 37-45.

Muchlisin, Z.A., M. Nazir, M. Musman. 2012. Pemetaan potensi daerah untuk pengembangan kawasan minapolitan di beberapa lokasi dalam Provinsi Aceh: suatu kajian awal. Mapping of the potencial locations for developing of minapolitan region in Aceh Province: a preliminary study. Depik, Vol. 1 (1): 68-77.

Nurmarini, V.M. 2018. The Development of Minapolitan Area Based on Participatory Planning in Increasing Fishermen Community Welfare: Study In Minapolitan Area of Sei Ijum Raya Village, East Kotawaringin Regency. RJOAS, Vol. 5(77): 162170.

Rudiono, P. Harsasto, dan A. Taufiq. 2013. Evaluasi Pelaksanaan Program Minapolitan Tahun 2009-2011 di Kabupaten Banyumas. Journal of Politic and Government Studies. Vol. 3 (1): 66 -75.Apriliani, Tenny, Tikkyrino Kurniawan, dkk. 2011. Jurnal Identifikasi Permasalahan Dan Peluang Perbaikan Pengembangan Kawasan Minapolitan Di Kabupaten Gowa. J. Sosek KP Vol. 6 No. 2.

Republik Indonesia. 2007. Undang-Undang No. 26 Tahun 2007 tentang Penataan Ruang, Lembaran Negara RI Tahun 1992, No. 115. Sekretariat Negara.. Jakarta.

Republik Indonesia. 2010. Keputusan Bupati Banjarnegara Nomor 050/344 Tahun 2010 dan Pembentukan Kelompok Kerja (POKJA) berdasarkan Keputusan Bupati Nomor 050/342 Tahun 2010 tentang penetapan lokasi pengembangan kawasan minapolitan. Banjarnegara.

Republik Indonesia. 2011. Perda Kabupaten Banjarnegara No. 11 tahun 2011 tentang kawasan Minapolitan Rajapurbawa sebagai sentra kawasan usaha perikanan. Jakarta.

Republik Indonesia. 2012. Peraturan Menteri Kelautan dan Perikanan Nomor: PER.18/MEN/2012 Tentang Pedoman Penyusunan Rencana Induk Pengembangan Kawasan Minapolitan. Jakarta. 